DOI: http://dx.doi.org/10.22483/2177-5796.2018v20n2p371-381

\title{
Paulo Freire na FAFI e na Uniso: depoimentos
}

\author{
Sonia Chébel Mercado Sparti
}

Resumo: Este artigo descreve aspectos da presença do educador Paulo Freire na cidade de Sorocaba, por seis vezes, como convidado da Faculdade de Filosofia, Ciências e Letras de Sorocaba (FAFI) e da Universidade de Sorocaba (Uniso), da qual a FAFI foi embrião. Caracteriza-se como depoimento, uma vez que estive presente em todas essas vezes, tendo oportunidade de gravar sua fala e de transcrevê-la, em cinco delas. Inclui também informações a respeito da circulação de suas ideias educacionais, entre docentes e universitários/as dessas duas instituições de ensino superior, durante seu período de exílio. Termina relatando, suscintamente, meus encontros com ele na Pontifícia Universidade Católica de São Paulo (PUCSP), onde ele foi professor, e minhas lembranças de seu falecimento, em maio de 1997.

Palavras-chave: Educação. Alfabetização. Opressão. Conscientização. Liberdade.

\section{Paulo Freire at FAFI and Uniso: testimony}

Abstract: This article describes the aspects of the educator Paulo Freire presence in Sorocaba city, for six times, as guest of the Faculdade de Filosofia, Ciências e Letras de Sorocaba (FAFI) and of the Universidade de Sorocaba (Uniso) as well, from which FAFI has belong. It has an aspect of testimony, once I was part of all these six times, having the opportunity of recording and transcripting his speech in five of them. It also includes information about his educational ideas circulation among teachers and academics of these two higher education institutions during his exile period. It ends telling, briefly, my meetings with him at Pontifícia Universidade Católica de São Paulo (PUC-SP), where he was professor, and my memories about his death, in May 1997.

Keywords: Education. Literacy. Oppression. Awareness. Liberty. 
SPARTI, Sonia Chébel Mercado. Paulo Freire na FAFI e na Uniso: depoimentos.

O grande educador brasileiro Paulo Reglus Neves Freire ${ }^{1}$, mais conhecido como Prof. Paulo Freire, esteve por seis vezes na cidade de Sorocaba/SP, sendo cinco delas na Faculdade de Filosofia, Ciências e Letras de Sorocaba (FAFI) e uma delas, na Universidade de Sorocaba (Uniso), nas seguintes datas: 24 e 31 de outubro de 1980; 07 de novembro de 1980; 07 de novembro de 1981; 26 de junho de 1985 e 21 de outubro de 1994. Em todas elas eu tive o privilégio de estar presente e, em cinco delas, de gravar e transcrever sua fala.

No entanto, durante seu período de exílio e antes mesmo da sua presença física ocorrer em Sorocaba, suas ideias, reflexões e práticas pedagógicas sobre educação e alfabetização de adultos já povoavam os pensamentos dos/as universitários/as da Faculdade de Filosofia, Ciências e Letras de Sorocaba (FAFI), principalmente a partir do ano de 1967, data da publicação do seu livro Educação como prática de liberdade (Rio de Janeiro: Paz e Terra, 1967). Caloura do curso de Pedagogia, ganhei de presente de aniversário um exemplar deste livro, dos amigos veteranos do curso de Filosofia, Lino (José Lino de Oliveira Bueno) e Zeca (José Antonio dos Santos), em junho de 1967, com a seguinte dedicatória: "Para que a nossa juventude esteja sempre a serviço da liberdade do povo brasileiro". Que atualidade!

Além das discussões em sala de aula, nos cursos de licenciatura em Pedagogia, Filosofia, História, Geografia e Letras, o pensamento de Paulo Freire era aprofundado nas reuniões da JUC (Juventude Universitária Católica), sob orientação do Padre Osvaldo Bazzo. Durante o período em que estudei na Faculdade de Filosofia (1967 a 1970), fiz parte da JUC e recebi documentos do Centro de Documentação do Movimiento Internacional de Estudiantes Catolicos (M.I.E.C.), com sede em Montevideo, no Uruguay. Dos muitos documentos recebidos em 1968, somente três deles ainda conservo comigo porque, depois de uma "visita" policial inesperada que Padre Bazzo recebeu em sua paróquia, e até por sua orientação, eles foram "enterrados" no quintal de casa, devidamente embalados com sacos plásticos, em cova de um metro e meio de profundidade, durante dois anos. São eles: Evangelio y Justícia Social; Los Estudiantes en la Transformacion de la Sociedad Brasileña; Introduccion a una Pedagogia de la Pastoral Universitaria.

\footnotetext{
${ }^{1}$ Paulo Reglus Neves Freire nasceu em Recife, PE, em 19 de setembro de 1921. Começou a escrita das palavras utilizando gravetos das mangueiras, no chão do quintal da casa onde morava. Formou-se em Direito porque, nessa época, Pernambuco não possuía curso superior de formação de educador. Durante seus 16 anos de exílio na Bolívia, Chile, Estados Unidos, Suíça e África, lecionou em diversas universidades estrangeiras e trabalhou na sede do Conselho Mundial das Igrejas, em Genebra, retornando definitivamente ao Brasil em junho de 1980 . Até o momento é o brasileiro que recebeu o maior número de títulos de Doutor Honoris Causa (41), outorgados por instituições acadêmicas brasileiras e estrangeiras.
} 
No primeiro desses documentos Evangelio y Justícia Social (1968, p. 09) há uma informação sobre Paulo Freire e seu conceito de conscientização:

Infelizmente, nos estamos dando el lujo de exportar a los grandes brasileños. A partir de 1964 exportamos más de 260 grandes profesores y técnicos; y para los Estados Unidos, que concentran hoy el cerebro técnico del mundo, exportamos 90 (el pobre enriquece al rico). Uno de estos grandes brasileños es Paulo Freire, a quien el Episcopado chileno pidió que lo asesorase en la evangelización realista del hombre chileno, y que hoy se encuentra ayudando a la liberación democrática de los países africanos. Paulo Freire decía que conscientizar el hombre es darle uma conciencia crítica, capaz de comprender las contradicciones del régimen en que vive, de juzgarlo, de conquistar una independência frente a este régimen, y ser capaz de decidir por sí, usando su derecho de autodeterminación. Dar al hombre uma conciencia crítica y la posibilidad de autodeterminación es conscientizalo. Esta conscientización es uma exigencia de justicia social. Por eso es evangélica, a mi modo de ver.

O segundo deles analisa as características gerais do movimento universitário brasileiro, a reforma universitária e a sociedade brasileira, citando, inclusive, o fracasso da greve ocorrida no CRUSP (Centro Residencial da Universidade de São Paulo), em 1965. No terceiro, dentre os pensadores que embasaram a construção de uma Pedagogia da Pastoral Universitária, podem ser encontrados: Pierre Furter em sua obra Educação e reflexão (Petrópolis: Vozes, 1966) e Paulo Freire, em Educação como prática de liberdade (Rio de Janeiro: Paz e Terra, 1967), dentre outras obras.

Depois de treze anos desse primeiro contato com as ideias freireanas, e da leitura de outros livros seus, tive oportunidade de conhecer Paulo Freire e sua primeira esposa Elza ${ }^{2}$, também professora, pois a Faculdade de Filosofia, Ciências e Letras de Sorocaba houve por bem realizar o Projeto Vivendo e Aprendendo. Esse Projeto consistiu em três seminários coordenados pelo próprio Paulo Freire, em três semanas consecutivas (24 e 31 de outubro e 07 de novembro de 1980), complementados com seu retorno à Faculdade, em 07 de novembro de 1981.

Idealizado pelo Prof. Aldo Vannucchi ${ }^{3}$, então professor e diretor da Faculdade de Filosofia, que havia trabalhado com Paulo Freire no Conselho Mundial das Igrejas, em Genebra, na Suíça, durante seu período de exílio, esse Projeto também contou com duas exposições

\footnotetext{
${ }^{2}$ Elza Maria Costa de Oliveira, professora primária, primeira esposa de Paulo Freire, nasceu em 1916 e faleceu em 24 de outubro de 1986.

${ }^{3}$ Aldo Vannucchi foi professor e diretor da Faculdade de Filosofia, Ciências e Letras de Sorocaba, embrião da atual Universidade de Sorocaba (Uniso). Mestre em Filosofia e Teologia pela Universidade Gregoriana de Roma, licenciado em Pedagogia e autor de diversos livros, foi Reitor da Uniso (de setembro de 1994 a janeiro de 2010) sendo, atualmente, assessor especial da reitoria e ouvidor da universidade.
} 
SPARTI, Sonia Chébel Mercado. Paulo Freire na FAFI e na Uniso: depoimentos.

introdutórias sobre educação como prática de liberdade e conscientização, proferidas pelos professores da FAFI, Wlademir dos Santos ${ }^{4}$ e Aldo Vannucchi.

Nesse período em que Paulo Freire coordenou esses seminários, o prédio da Faculdade estava passando por necessárias reformas, do piso ao telhado, e o Prof. Aldo passou a dividir sua sala comigo, então vice-diretora. Sobre minha mesa de trabalho, uma necessária máquina de escrever Olivetti, Lexon 80, fato que levava as pessoas a me cumprimentarem como sendo a nova secretária do Prof. Aldo. Menos uma... Paulo Freire. Na primeira vez em que ele chegou à Faculdade, acompanhado da esposa Elza, e foi encaminhado à diretoria, Prof. Aldo estava na biblioteca. Eu os recebi, profundamente emocionada, e pedi para uma funcionária avisar o Prof. Aldo. Então Paulo Freire me perguntou: "E o que você faz aqui, filha”? Nunca me esqueci desse primeiro contato e muito me emociono ao relembrá-lo.

Durante o primeiro seminário ${ }^{5}$, Paulo Freire surpreendeu a todos dizendo que em Sorocaba residia uma pessoa muito querida sua, o Dr. José Cardoso, que foi seu professor de Geografia, em Recife. Pessoa muito conhecida em Sorocaba, o paraibano Dr. José Pereira Cardoso era advogado da Companhia Nacional de Estamparia (Cianê) e um dos fundadores da Faculdade de Direito local. Particularmente, Dr. Cardoso era pessoa do meu conhecimento porque sua esposa tinha sido colega de classe da minha mãe, no curso ginasial, e porque eu tinha sido "mãe de leite" de um neto seu, durante meses, a partir do final de 1977, por ocasião do nascimento de minha segunda filha. Mas, até então, os sorocabanos desconheciam o fato dele ter sido professor desse aluno ilustre, em terras pernambucanas, no Colégio Osvaldo Cruz.

Em outro momento desse seminário, falando sobre o hábito dos universitários citarem, com frequência, o pensamento de muitos autores, mas nada falarem sobre o próprio pensamento a respeito dos acontecimentos, Paulo Freire afirmou que estava na hora de "abandonar as muletas de Malinowski”. Outro impacto. Muletas? Bronislaw Kasper Malinowski (1884-1942), antropólogo polonês criador da antropologia social, para quem as instituições humanas devem ser analisadas no contexto de uma cultura, era um dos autores muito citados por professores universitários e estudantes, principalmente dos cursos de Pedagogia, Filosofia e História. Nessa

\footnotetext{
${ }^{4}$ Wlademir dos Santos lecionou no curso de Pedagogia da Faculdade de Filosofia, Ciências e Letras de Sorocaba (FAFI) e na Universidade de Sorocaba (Uniso). Mestre em Educação pela Pontifícia Universidade Católica de São Paulo (PUC-SP), autor da obra A verdade sobre o vestibular (São Paulo: Ática, 1988), nasceu em 1935 e faleceu em 2007, em Sorocaba, SP.

${ }^{5}$ Realizado no Salão de Recursos Audiovisuais da faculdade, situado no quarto andar no prédio da biblioteca.
} 
época, se uma aula ou uma conferência não incluísse uma citação de Malinowski para sustentar uma afirmação, não era digna de crédito...

Durante o segundo seminário, Paulo Freire abordou, dentre muitos outros assuntos, a libertação das colônias portuguesas na África, e a sua participação nesse processo. Falou sobre Guiné-Bissau, Cabo Verde, São Tomé e Príncipe, e também um pouco sobre Angola. No terceiro seminário esclareceu vários conceitos de sua teoria pedagógica, dentre eles, o de inédito viável.

Perguntado sobre seu método de alfabetização de adultos, e sobre sua experiência a partir da palavra geradora tijolo, Paulo Freire, na conferência de $1981^{6}$, iniciou sua resposta descrevendo o cenário em que uma dessas experiências ocorreu. Disse ele que após um longo dia, em que trabalharam durante 11 ou 12 horas, os operários da construção civil, nordestinos e analfabetos, em sua maioria, apelidados de "candangos", tomavam a última refeição do dia, nos refeitórios das construtoras. Muitos deles tinham vindo para Brasília, acompanhados das respectivas esposas, para que trabalhassem na cozinha industrial desses alojamentos. Finda essa alimentação, aqueles e aquelas que ainda tivessem força e motivação para participarem do processo de alfabetização, permaneciam no refeitório. A mesa era formada por duas tábuas compridas, sobre cavaletes. Os bancos também eram de tábuas. Uma pequena lousa retangular, de cor preta, com, aproximadamente, um metro de comprimento, era iluminada por um único bico de luz.

A palavra geradora tijolo havia sido escolhida a partir das conversas com essas pessoas, em dias anteriores, sobre o trabalho que realizavam em Brasília: "eu ajudo a fazer o tijolo"; "eu transporto o tijolo"; "eu assento o tijolo". Também já tinham entrado em contato com as famílias silábicas dessa palavra: ta te ti to tu; ja je ji jo ju; la le li lo lu. Nessa aula descrita por Paulo Freire, esses trabalhadores e essas trabalhadoras foram convidados, pela educadora, a criarem palavras a partir dessas famílias silábicas. Então uma mulher analfabeta diz “Tito”, apontando as sílabas ti e to. "O que é Tito" pergunta a educadora, que tinha acabado de fazer o curso com Paulo Freire. “Tito, primeiro, é nome de gente e, em segundo, é o papé com que nóis vota”. Essa mulher analfabeta tinha radinho de pilha e havia ouvido que Tito, o imperador da Yugoslávia, estava visitando o Brasil. A educadora não corrigiu essa mulher, naquele momento da criação da palavra, porque seria um desastre se corrigisse e falasse que a palavra correta era título, pois

\footnotetext{
${ }^{6}$ Realizada no Salão Nobre da faculdade, no andar térreo, em tarde bastante chuvosa. 
ninguém mais iria querer formar novas palavras. A correção viria com o tempo, em outro momento. Paulo Freire, que estava presente nessa aula, conta que, a seguir, um homem se levantou do seu lugar, foi até a lousa e, olhando para essa mulher, disse: tu ja le. Ele ultrapassou a palavra e criou a sentença. A mesma observação em relação à correção é feita aqui, pois quando estiverem aprendendo a conjugar os verbos, descobrirão que o correto é tu já lês, por se tratar da segunda pessoa do singular.

E assim Paulo Freire foi maravilhando a todos e todas que tiveram oportunidade de participar desses seminários, pela convicção que permeava seu discurso, pela clareza das explicações, pelos gestos firmes e marcantes, pelo respeito às pessoas e às perguntas formuladas.

Na condição de vice-diretora da Faculdade (1980-1984) e encarregada do Setor de Recursos Audiovisuais, providenciei a gravação, em áudio, desses seminários e dessas palestras. Posteriormente, me encarreguei da transcrição dessas fitas cassete, em mais de 100 horas de trabalho. A primeira revisão foi feita pelo Prof. Aldo. A segunda, pelo próprio Paulo Freire, que autorizou sua publicação. E o livro Paulo Freire ao vivo, reprodução fiel das duas palestras introdutórias, dos três seminários de 1980 e da conferência de 1981, foi publicado em 1983 (São Paulo: Loyola, 1983). As várias fitas cassete, devidamente identificadas, foram incorporadas ao acervo sonoro desse Setor, ao lado de outras com as vozes, por exemplo, da escritora Lygia Fagundes Telles ${ }^{7}$, do então governador André Franco Montoro ${ }^{8}$, e do jurista Dalmo de Abreu Dallari ${ }^{9}$. E foi com indignação que, recentemente, recebi a notícia de que a caixa com todo esse

\footnotetext{
${ }^{7}$ Lygia Fagundes Telles, nascida em 19 de abril de 1923, na cidade de São Paulo, é escritora, advogada, romancista e contista. Dentre muitos prêmios recebidos estão quatro Prêmios Jabuti (1966, 1974, 1996, 2001), quatro Prêmios da Associação Paulista dos Críticos de Arte (1973, 1980, 2000, 2007), o Prêmio Camões (2005) e o Juca Pato (2008). Das suas obras, Ciranda de Pedra (1955) e As Meninas (1973) podem ser consideradas as mais conhecidas. Esteve por duas vezes proferindo palestra aos alunos e alunas do Curso de Letras da Faculdade de Filosofia de Sorocaba, na década de 80.

${ }^{8}$ André Franco Montoro nasceu em 14 de julho de 1916, em São Paulo. Formou-se em Filosofia e Pedagogia, na Faculdade de Filosofia, Ciências e Letras de São Bento e, em Direito, na Faculdade de Direito da Universidade de São Paulo. Um dos fundadores da Juventude Universitária Católica (JUC), lecionou na PUC-SP, foi jurista e político. Foi eleito senador, deputado federal e $27^{\circ}$ governador do Estado de São Paulo (1983-1987). Como governador tomou decisões que priorizaram a educação. Faleceu em 17 de julho de 1999, em São Paulo. Proferiu palestra na FAFI, em junho de 1980, sobre Cristianismo e Trabalho, em comemoração ao centenário de nascimento de Dom José Carlos de Aguirre, primeiro bispo de Sorocaba.

${ }^{9}$ Dalmo de Abreu Dallari, jurista, professor emérito da Faculdade de Direito da USP, da qual foi diretor, nasceu em 31 de dezembro de 1931, em Serra Negra, SP. Em 1996 tornou-se professor catedrático da UNESCO, na cátedra de Educação para a Paz. A partir de 1972 ajudou a organizar a Comissão Pontifícia de Justiça e Paz da Arquidiocese de São Paulo. Em junho de 1980, proferiu palestra na FAFI sobre Cristianismo e Liberdade, em comemoração ao centenário de nascimento de Dom José Carlos de Aguirre.
} 
acervo foi "extraviada", quando da mudança do campus Trujillo da Uniso para a Cidade Universitária... Se essas fitas tivessem sido preservadas e convertidas para CDs, hoje seriam importantes fontes de pesquisas.

Paulo Freire retornaria a Sorocaba em 1985, para receber uma homenagem. No entanto, no ano anterior, a Faculdade de Filosofia contou com a presença da educadora Madalena Freire ${ }^{10}$, filha de Paulo Freire, para uma conversa sobre alfabetização de crianças e lançamento do seu livro A paixão de conhecer o mundo (Rio de Janeiro: Paz e Terra, 1983). Esse livro relata seu cotidiano escolar com as crianças da Escola da Vila, em São Paulo, embasado por vários pensadores, dentre eles, Jean Piaget ${ }^{11}$ e Paulo Freire. Esse encontro ocorreu em 20 de março de 1984, em uma promoção do Departamento de Educação da Faculdade de Filosofia. Nessa ocasião, eu estava na Chefia desse Departamento e o Prof. Aldo Vannucchi continuava diretor da Faculdade.

Em 20 de maio de 1985, alunos e alunas do Curso de Pedagogia da Faculdade de Filosofia, reunidos em Assembleia, decidiram reativar o Centro de Estudos Pedagógicos (CEP), órgão vinculado ao Centro Acadêmico e muito operante na década de 1960. E aqui cabe uma explicação. Cada curso da Faculdade de Filosofia, nessa época, tinha seu Centro de Estudos. Esses "Centrinhos", como habitualmente eram chamados, tinham por objetivo aprofundar o estudo de alguns assuntos tratados em aula, sob orientação de um/a professor/a. E assim foram criados o Centro de Estudos Literários "Guilherme de Almeida" (CELGA); Centro de Estudos Geográficos "Emmanuel de Marconi” (CEGEM); Centro de Estudos Históricos "Varnhagen" (CEHV); Centro de Estudos Matemáticos “Osvaldo Sangiorgi” (CEMOS); Centro de Estudos

\footnotetext{
${ }^{10}$ Madalena Freire Weffort, filha mais velha de Paulo Freire, é pedagoga (formada pela USP), professora primária e arte-educadora. Para alfabetizar crianças utiliza a metodologia de alfabetização de adultos criada por seu pai. A palavra geradora para as crianças da Escola da Vila, em São Paulo, foi jaca, a fruta desconhecida delas e que despertou grande curiosidade. Para as crianças de uma classe multiseriada em Carapicuiba/SP, que quase não comiam frutas, foi pipa, o brinquedo preferido. E para as que residiam em Diadema/SP, em rua não pavimentada, foi lama, com a qual conviviam em dias chuvosos.

${ }^{11}$ Jean Piaget nasceu em Neuchâtel, na Suíça, em 09 de agosto de 1896. Depois da licenciatura e do doutorado em Ciências Biológicas pela Universidade de Neuchâtel, foi estudar Psicologia em Zurique e Paris, onde trabalhou no laboratório de Psicologia de Alfred Binet. Lecionou Psicologia na Universidade de Genebra, de 1929 a 1952. Publicou vários livros a partir das suas pesquisas realizadas sobre o desenvolvimento cognitivo da criança, sozinho ou com colaboradores. Em 1955 fundou o Centro Internacional de Epistemologia Genética, que dirigiu até seu falecimento, em 16 de setembro de 1980. Recebeu 30 títulos de Doutor Honoris Causa, dentre os quais o da Universidade do Brasil (1949), atual Universidade Federal do Rio de Janeiro (UFRJ). Uma curiosidade: o trem que liga Genebra e Neuchâtel (uma hora de viagem, aproximadamente) estampa, em seu interior, as principais afirmações de Piaget.
} 
Filosóficos (CEF) e Centro de Estudos Pedagógicos (CEP). Esses dois últimos não levavam o nome de um Patrono, em virtude da falta de acordo entre alunos e alunas para sua definição. No caso dos alunos e alunas do Curso de Pedagogia, os nomes sugeridos foram: Decroly, Pestalozzi, Montessori, Froebel, Makarenko, Comenius, Anísio Teixeira, dentre outros. No entanto, nesse maio de 1985, o nome do educador Paulo Freire foi escolhido por unanimidade.

O passo seguinte foi convidar Paulo Freire para vir receber o diploma de Patrono do Centro de Estudos Pedagógicos "Paulo Freire" (CEPPF), o que ocorreu um mês depois, em 26 de junho desse mesmo ano, no salão nobre, em reunião presidida pelo Prof. Aldo Vannucchi, diretor da Faculdade. Na ata lavrada nessa ocasião, constam os seguintes dizeres:

O Prof. Paulo Freire agradeceu, sensibilizado, a homenagem que estava sendo feita, reafirmando sua responsabilidade em cada vez mais se preocupar com as coisas da educação. Enfatizou que com essa homenagem, os alunos do curso de Pedagogia deveriam ser como ele: um contestador. Premiou o Centro de Estudos Pedagógicos com uma coleção de suas obras e de seus amigos nacionais e internacionais.

Após essas palavras, Antonio Celso do Amaral Silva, então aluno do curso de Pedagogia e Presidente do CEPPF, entregou o Diploma de Patrono ao Prof. Paulo Freire. Nessa mesma ocasião, foi entregue a mim, então Chefe do Departamento de Educação, o primeiro Diploma de Sócio Benemérito do Centro de Estudos Pedagógicos "Paulo Freire". Sensibilizada e agradecida, pedi para Paulo Freire autografar meu Diploma, no que fui prontamente atendida. Infelizmente, o CEPPF não sobreviveu até o ano seguinte, em grande parte pela falta de tempo dos alunos e alunas de agora que, diferentemente daqueles da década de 1960, apresentavam outro perfil, trabalhando durante o dia e estudando à noite. Esse livro de atas do CEPPF foi entregue à Secretaria da Faculdade e hoje pode ser consultado na Secretaria Acadêmica da Uniso.

Em junho de 1992 (dias 22 a 25), houve uma Assembleia Geral promovida pela Conferência Nacional dos Bispos do Brasil (CNBB), em Itaici, município de Indaiatuba, no Estado de São Paulo, para criar a Pastoral da Educação. Convidado a orientar os trabalhos, Paulo Freire compareceu com parte de sua equipe: Profa. Dra. Ana Maria Saul e Prof. Dr. Antonio Chizzotti, eles três docentes no Programa de Pós-Graduação em Educação da PUC-SP (Pontifícia Universidade Católica de São Paulo). Tendo recentemente deixado a direção da Faculdade de Filosofia por término de mandato (1988-1992), eu participei desse Encontro representando o Laicato da Diocese de Sorocaba, por indicação de seu Arcebispo Dom José Lambert, também 
Presidente da Fundação Dom Aguirre, mantenedora da FAFI. Nessa oportunidade, levei a Paulo Freire o abraço do Prof. Aldo e da Faculdade de Filosofia de Sorocaba.

A última vez em que Paulo Freire esteve em Sorocaba foi na tarde de 21 de outubro de 1994, nas dependências do Teatro Municipal de Sorocaba, em uma promoção conjunta da Universidade de Sorocaba e das Secretarias Municipais da Educação e da Criança e do Adolescente, da Prefeitura Municipal de Sorocaba. Foi o primeiro grande evento da recém-criada Universidade de Sorocaba, então com apenas um mês de vida, sendo o Prof. Aldo Vannucchi seu primeiro Reitor. Formada a mesa diretora dos trabalhos, observei não haver nenhum indício de gravação dessa palestra, em áudio ou em vídeo, o que considerei imperdoável esquecimento. Então, da quinta fileira da plateia, onde eu me encontrava, tirei meu minigravador Panasonic da bolsa, coloquei pilhas e fita cassete e gravei essa palestra.

Tencionava transcrevê-la de imediato, o que não ocorreu por vários motivos: defesa do segundo mestrado em Psicologia da Educação, na PUC-SP (1995), início do doutorado, nessa mesma área e universidade (1996), grande número de aulas semanais ministradas na Uniso e na PUC-SP, função de vice-diretora comunitária do campus da PUC-SP em Sorocaba (1997-2001), participação de várias reuniões dos órgãos colegiados nessas duas universidades, dentre muitos outros. Foi somente em julho de 2017, objetivando reorganizar meu acervo de quase 100 fitas cassetes, que encontrei essa preciosidade. Coloquei a fita no gravador e as vozes do Prof. Aldo e de Paulo Freire estavam nítidas, como se a gravação fosse recente, apesar dos 23 anos que haviam passado. Então transcrevi a fita e providenciei sua gravação em cd, para maior conservação, distribuindo cópias para pessoas interessadas, incluindo a educadora Nita Freire ${ }^{12}$, viúva de Paulo Freire.

Paulo Freire não mais retornou a Sorocaba, até seu falecimento em 1997, mas eu continuei tendo o privilégio de encontrá-lo na PUC de São Paulo, onde ele lecionava no Programa de Pós-Graduação em Educação/Supervisão e Currículo e onde eu fazia o mestrado (1992-1995) e, posteriormente, o doutorado em Educação/Psicologia da Educação. Para mim era um impacto cada vez que eu o encontrava na lanchonete do $3^{\circ}$ andar, no elevador, ou no próprio

\footnotetext{
${ }^{12}$ Ana Maria Araújo Freire, também conhecida como Nita Freire, nascida no estado de Pernambuco, é Mestre (1980) e Doutora (1994) em Educação, pela Pontifícia Universidade Católica, de São Paulo (PUC-SP). Casou-se com Paulo Freire em agosto de 1988. Professora universitária, atualmente se dedica a organizar, publicar e divulgar a obra de Paulo Freire, como sucessora legal do educador.
} 
SPARTI, Sonia Chébel Mercado. Paulo Freire na FAFI e na Uniso: depoimentos.

$4^{\mathrm{o}} \operatorname{andar}^{13}$, onde ocorriam as aulas da pós-graduação. Certa vez, um membro do Centro Acadêmico, interrompendo sua aula, pediu a Paulo Freire autorização para dar um aviso aos alunos/as. Prontamente ele respondeu que autorizava, mas que perguntaria a seus alunos/as se eles/as também autorizavam, dando a entender que não poderia decidir pela classe. Esse fato desencadeou em mim profunda reflexão, pois eu nunca havia agido desse modo. Imperdíveis também foram os seminários e colóquios com a participação de Paulo Freire, Peter McLaren ${ }^{14}$, Moacir Gadotti ${ }^{15}$, dentre outros.

Paulo Freire faleceu na manhã do dia 02 de maio de 1997. Eu estava lecionando no curso de Enfermagem da PUC-SP/campus Sorocaba, quando a triste notícia chegou. Paulo Freire foi velado no saguão do Teatro da Universidade Católica (TUCA), com um giz branco entre as mãos. Autoridades, reitoria, professores/as, alunos/as, funcionários/as, religiosos, imprensa nacional e internacional lotavam as dependências do teatro. O então Reitor da PUC-SP, Prof. Dr. Antonio Carlos Caruso Ronca, foi o anfitrião desse triste acontecimento. O então Presidente da República, Fernando Henrique Cardoso, esteve representado pela sua esposa, Ruth Cardoso. Paulo Freire foi sepultado na manhã do dia 03 de maio, no Cemitério da Paz, em São Paulo, após poema declamado pelo amigo amazonense Thiago de Mello ${ }^{16}$.

Finda a cerimônia, eu estava trocando rápidas palavras com Eduardo Suplicy ${ }^{17}$ e Marta Suplicy $^{18}$, quando uma mão amiga tocou o meu ombro. "Como é difícil para um professor enterrar um aluno", disse-me Dr. José Pereira Cardoso ${ }^{19}$.

\footnotetext{
${ }^{13}$ Apelidado de Olimpo pelos/as pós-graduandos/as por ser o local da "morada dos deuses", denominação afetiva dada aos importantes professores e pesquisadores dos vários Programas de Mestrado e Doutorado, tendo como referência a mitologia grega.

${ }^{14}$ Peter McLaren nasceu em 02 de agosto de 1948 em Toronto, Canadá. Professor da Universidade da Califórnia, Los Angeles, é autor de numerosa obra, principalmente sobre Pedagogia Crítica. Suas ideias educacionais convergem com as de Paulo Freire.

${ }^{15}$ Moacir Gadotti é diretor do Instituto Paulo Freire, cuja sede está situada na cidade de São Paulo (Rua Cero Corá, 550, $2^{\circ}$ andar, conj. 22, Altos da Lapa - 05061-100 - (11) 3021.5536). Doutor em Ciências da Educação pela Universidade de Genebra, Livre-docente pela Unicamp, nasceu em Rodeio/SC, em 21 de outubro de 1941. É autor de vários livros.
}

${ }^{16}$ Amadeu Thiago de Mello é poeta e tradutor. Tem obras traduzidas para mais de trinta idiomas. Nasceu na cidade de Barreirinha, no Amazonas, no dia 30 de março de 1926. Cursou até o $4^{\circ}$ da Faculdade de Medicina, no Rio de Janeiro, trocando essa profissão pela vocação de poeta. Perseguido pela ditadura militar, viveu longo período de exílio no Chile, onde se tornou grande amigo do também poeta Pablo Neruda. Em seu livro Educação como prática de liberdade, Paulo Freire colocou o poema "Canção Para os Fonemas da Alegria", escrito por Thiago de Mello, em Santiago do Chile, no verão de 1964. Também é dessa data seu belíssimo poema "Os Estatutos do Homem" (Ato Institucional Permanente), leitura obrigatória dos universitários da FAFI, na década de 1960.

${ }^{17}$ Eduardo Matarazzo Suplicy é economista, professor universitário, administrador de empresas e político, tendo sido senador durante 24 anos. Atualmente é vereador do município de São Paulo, em segundo mandato. Nasceu no dia 


\section{Referências}

EVANGELIO y Justícia Social. 1968. (Documento do acervo de Sonia Chebel Mercado Sparti)

FREIRE, Paulo. Educação como prática de liberdade. Rio de Janeiro: Paz e Terra, 1967.

FREIRE, Madalena. A paixão de conhecer o mundo. São Paulo: Paz e Terra, 1983.

FURTER, Pierre. Educação e reflexão. Petrópolis: Vozes, 1966.

SANTOS, Wlademir dos. A verdade sobre o vestibular. São Paulo: Ática, 1988.

VANNUCCHI, Aldo (Org.). Paulo Freire ao vivo. São Paulo: Loyola, 1983.

\section{Obras consultadas}

FREIRE, Ana Maria Araújo. Paulo Freire: uma história de vida. Rio de Janeiro: Paz e Terra, 2017.

GADOTTI, Moacir. Convite à leitura de Paulo Freire. São Paulo: Scipioni, 1991.

GADOTTI, Moacir. Paulo Freire: uma biobibliografia. São Paulo: Cortez, 1996.

KRÜGER, Marcos Frederico. Thiago de Mello. São Paulo: Global, 2009.

SPARTI, Sonia Chébel Mercado. Apontamentos da autora.

Sonia Chébel Mercado Sparti

Fundação Dom Aguirre | Conselheira da Fundação Dom Aguirre

Sorocaba | SP | Brasil. Contato: chebel.sonia@gmail.com

ORCID 0000-0003-4642-0249

Artigo recebido em: 3 jul. 2018 e

aprovado em: 10 jul. 2018.

21 de junho de 1941, em São Paulo e foi casado com Marta Suplicy, de 1964 a 2001. Esteve diversas vezes na FAFI/Uniso proferindo palestra sobre economia e política.

${ }^{18}$ Marta Teresa Smith de Vasconcellos Suplicy é política, psicanalista e sexóloga. Nasceu em 18 de março de 1945, na cidade de São Paulo. Foi a 48 a prefeita da cidade de São Paulo (2001 a 2005). Também foi Ministra da Cultura e do Turismo. Atualmente exerce o cargo de senadora da república por São Paulo. Esteve duas vezes na Faculdade de Filosofia, Ciências e Letras de Sorocaba (FAFI), na década de 1980, proferindo palestra sobre Educação Sexual, aos alunos e alunas das diversas licenciaturas, principalmente do curso de Pedagogia.

${ }^{19}$ José Pereira Cardoso, nascido em Princesa Isabel, na Paraíba, em 11 de maio de 1911, também professor do economista Celso Furtado, no curso ginasial, reencontrou Paulo Freire em 01 de julho de 2005.

Quaestio, Sorocaba, SP, v. 20, n. 2, p. 371-381, ago. 2018 